\title{
Anxiety and depression among gastroenterologists: an online survey in Bangladesh
}

\author{
Md Abdul Mumit Sarkar ${ }^{1}$, Madhusudan Saha ${ }^{2}$, Mushtaque Ahmad Rana ${ }^{3}$, Shasanka Kumar Saha ${ }^{4}$ \\ ${ }^{1}$ Department of Gastroenterology, Rajshahi Medical College, Rajshahi, Bangladesh \\ 2Department of Gastroenterology, North East Medical College, Sylhet, Bangladesh \\ ${ }^{3}$ Department of Gastroenterology, Bangladesh Medical College, Dhanmondi, Bangladesh \\ ${ }^{4}$ Department of Gastroenterology, M Abdur Rahim Medical College, Dinajpur, Bangladesh
}

Gastroenterology Rev 2021; 16 (4): 358-363

DOI: https://doi.org/10.5114/pg.2021.111585

Key words: anxiety, depression, gastroenterologist.

Address for correspondence: Md Abdul Mumit Sarkar MD, Department of Gastroenterology, Rajshahi Medical College, Rajshahi, Bangladesh, phone: +8801718242963, e-mail: mumitsarkar@gmail.com

\begin{abstract}
Introduction: Anxiety and depression negatively affect physicians' performance, leading to them make errors in service providing. Reports regarding the prevalence of anxiety and depression among specialist physicians are limited.

Aim: To assess the prevalence of anxiety and depression among gastroenterologists in Bangladesh.

Material and methods: This cross-sectional study was conducted among gastroenterologists in Bangladesh. Survey questionnaires, including general information and the Hospital Anxiety and Depression Scale (HAD), were sent to the gastroenterologists' email addresses. Responses were collected and analysed.

Results: Out of 166 gastroenterologists, 63 (37.9\%, mean age: $49.77 \pm 8.0$ years, $96.8 \%$ male, mean service length: 20.2 \pm 8.0 years, mean working length as specialists $13.2 \pm 7.2$ years) responded. In this series, symptom scores of $16(25.4 \%)$ and 13 (20.7\%) respondents were consistent with anxiety and depression, respectively. Nine (14.2\%) respondents had symptoms of both anxiety and depression. Anxiety was significantly more prevalent among gastroenterologists of the 41-50-years age group ( $p=$ $0.007)$, and those who were working as specialists less than or equal to 5 years $(p=0.014)$. Depression was also more common among gastroenterologists in the 41-50-years age group 7 (24.1\%), doing government service 10 (19.6\%), service length $\leq 15$ years $5(29.4 \%)$, and working as specialist less than or equal to 10 years 7 (31.8\%), but the difference was not significant.

Conclusions: Anxiety and depression are more prevalent among gastroenterologists than in the general population. Further studies should be done to determine the risk factors behind anxiety and depression among gastroenterologists so that adequate preventive measures can be taken.
\end{abstract}

\section{Introduction}

According to the World Health Organization (WHO) statement, depression will be the leading cause of disease burden in 2030 [1]. Another WHO statement showed that $3.6 \%$ and $4.4 \%$ of the world population suffered from depression and anxiety in 2015, respectively, with female predominance [2]. According to the National Mental Survey (April-June) 2019 of Bangladesh, the prevalence of anxiety and depression in the adult population was $4.5 \%$ and $6.7 \%$, respectively [3]. Physicians are more likely to suffer from anxiety and depression than the general population [4]. Previous studies conducted in different parts of the world reported varying results regarding the prevalence of anxiety and depression among physicians, ranging from $11 \%$ to $41 \%$ and from $11 \%$ to $60 \%$, respectively, depending on their type of service and practice [5-11]. A recent report in Bangladesh showed that $11 \%$ and $11.5 \%$ of postgraduate residents suffered from anxiety and depression [12]. Another study showed that the prevalence of depression among Bangladeshi Medical Students was about 39\% [13].

Stress and anxiety negatively affect physicians' performance $[14,15]$. It was seen that depressed residents more frequently make medication errors than non-depressed residents $[16,17]$. Moreover, there is a significant association between professional burnout and anxiety and depression [18].

As a part of the community of medical professionals, gastroenterologists are also at risk of suffering from men- 
tal health problems. Gastroenterologists perform various procedures in addition to giving medical consultations to patients. Errors in medication and intervention constitute a significant source of patient harm. Reports regarding the prevalence of anxiety and depression among specialist physicians are limited. So, it is necessary to perform additional studies to see the extent of anxiety and depression among physicians of different sub-specialties.

\section{Aim}

This study was carried out to see the prevalence of anxiety and depression among gastroenterologists in Bangladesh.

\section{Material and methods}

This cross-sectional study was conducted among the gastroenterologist of Bangladesh. The email IDs of all gastroenterologists were collected from the membership registry of the Bangladesh Gastroenterology Society. An online survey questionnaire with a forwarding letter including the aim of the survey was sent to them at the weekend of the second and last week of May 2020. The anxiety and depression of gastroenterologists were assessed by the Hospital Anxiety and Depression Scale (HAD), consisting of 7 anxiety and 7 depression items, with a maximum score of 21 for each [19]. A score of 11 or more on either scale was regarded as indicative of significant or overt anxiety or depression, whereas a score of 8-10 on either scale was regarded as borderline anxiety or depression. Responses to the survey were taken as their consent. Responses found within 4 weeks of the first message were collected and then analysed.

\section{Statistical analysis}

Statistical analysis was done using Statistical Package for Social Science (SPSS version 20). Means and percentages were calculated for continuous data, and the $\chi^{2}$ test was used to see the relationship between categorical data. $P$-value $<0.05$ was taken as significant. The study was approved by the Ethical Review Committee of Rajshahi Medical College, Bangladesh (Ref. RMC/ERC/2020/243/228).

\section{Results}

Questionnaires were sent to 166 gastroenterologists. Four emails could not be delivered. In total, 63 (37.95\%, mean age: $49.77 \pm 8.0$ years, $96.8 \%$ male) gastroenterologists responded. Table I shows the baseline characteristics of the participant gastroenterologists. Among them, 51 (81.0\%) were in government service. In addition to service, 62 (98.4\%) gastroenterologists were involved in private chamber practice. The respondents' service length varied from 5 years to 43 years (mean: $20.29 \pm 8.09$ ), and their working length as a gastroenterologist varied from 1 to 38 years (mean: $13.28 \pm 7.278$ ).

In this series, symptom scores of 47 (74.60\%), $13(20.6 \%)$, and $3(4.8 \%)$ respondents were consistent with normal, borderline, and overt anxiety, respectively (Table II), while symptom scores of 50 (9.4\%), $11(17.5 \%)$, and 2 (3.2\%) respondents were consistent with normal, borderline and overt depression, respectively (Table III). Among them, 9 (14.28\%) respondents had symptom scores consistent with both anxiety and depression (including borderline and overt cases).

The prevalence of anxiety (including borderline and overt) was significantly more prevalent among gastroenterologists of the $41-50$-years age group ( $p=0.007$ ) and those who were working as gastroenterologists for less than or equal to 5 years $(p=0.014)$. The preva-

Table I. Demographic characteristics of the gastroenterologists $(n=63)$

\begin{tabular}{|c|c|c|}
\hline Participant characteristics & $\begin{array}{l}\text { Number } \\
(N)\end{array}$ & $\begin{array}{c}\text { Percentage } \\
(\%)\end{array}$ \\
\hline Total respondents & 63 & \\
\hline Mean age-year (range) & $49.77(36-67)$ & \\
\hline \multicolumn{3}{|l|}{ Age distribution [years]: } \\
\hline$\leq 40$ & 6 & 9.52 \\
\hline $41-50$ & 29 & 46.03 \\
\hline$\geq 51$ and & 28 & 44.44 \\
\hline \multicolumn{3}{|l|}{ Sex: } \\
\hline Male & 61 & 96.80 \\
\hline Female & 02 & 03.20 \\
\hline \multicolumn{3}{|l|}{ Current employment: } \\
\hline Government service & 51 & 81.00 \\
\hline Private service & 10 & 15.90 \\
\hline $\begin{array}{l}\text { Retired from government } \\
\text { service }\end{array}$ & 02 & 03.20 \\
\hline Private practice & 62 & 98.40 \\
\hline \multicolumn{3}{|l|}{ Service length [years]: } \\
\hline$\leq 10$ & 6 & 9.52 \\
\hline $11-15$ & 11 & 17.46 \\
\hline $16-20$ & 19 & 30.16 \\
\hline$>20$ & 27 & 42.85 \\
\hline \multicolumn{3}{|c|}{ Length of service as specialist (Gastroenterologist) [years]: } \\
\hline$\leq 10$ & 8 & 12.70 \\
\hline $11-15$ & 14 & 22.22 \\
\hline $16-20$ & 29 & 46.03 \\
\hline$>20$ & 12 & 19.05 \\
\hline
\end{tabular}


Table II. Association between demographic characteristics and anxiety among gastroenterologists

\begin{tabular}{|c|c|c|c|c|c|}
\hline Participant characteristics & Number $(N)$ & Normal & Borderline anxiety & Overt anxiety & $P$-value \\
\hline Gastroenterologists & 63 & $47(74.6 \%)$ & $13(20.6 \%)$ & $3(4.8 \%)$ & \\
\hline \multicolumn{6}{|l|}{ Age [years]: } \\
\hline$\leq 40$ & 6 & $3(50.00 \%)$ & $1(16.66 \%)$ & $2(33.33 \%)$ & \\
\hline $41-50$ & 29 & $20(68.96 \%)$ & $8(27.58 \%)$ & $1(3.44 \%)$ & 0.007 \\
\hline$>50$ & 28 & $24(85.71 \%)$ & $4(14.28 \%)$ & 0 & \\
\hline \multicolumn{6}{|l|}{ Current employment: } \\
\hline Government & 51 & $37(72.55 \%)$ & $11(21.57 \%)$ & $3(5.88)$ & \\
\hline Private & 10 & $9(90)$ & $1(10 \%)$ & 0 & 0.623 \\
\hline Retired & 2 & $1(50.00 \%)$ & $1(50.00 \%)$ & 0 & \\
\hline \multicolumn{6}{|l|}{ Service length [years]: } \\
\hline$\leq 10$ & 6 & $4(66.66 \%)$ & $1(16.66 \%)$ & $1(16.66 \%)$ & \\
\hline $11-15$ & 11 & $7(63.63 \%)$ & $3(27.27 \%)$ & $1(9.09 \%)$ & 0.014 \\
\hline $16-20$ & 19 & $1263.15 \%)$ & $6(31.58 \%)$ & $1(5.26 \%)$ & \\
\hline$>20$ & 27 & $24(88.88 \%)$ & $3(11.11 \%)$ & 0 & \\
\hline \multicolumn{6}{|c|}{ Length of practice in gastroenterology [years]: } \\
\hline$\leq 5$ & 8 & $2(25.00 \%)$ & $4(50.00 \%)$ & $2(25.00 \%)$ & \\
\hline $6-10$ & 14 & $11(78.57 \%)$ & $2(14.28 \%)$ & $1(7.14 \%)$ & 0.287 \\
\hline $11-20$ & 29 & $24(82.76 \%)$ & $5(17.24 \%)$ & 0 & \\
\hline$>20$ & 12 & $10(83.33 \%)$ & $2(16.67 \%)$ & 0 & \\
\hline
\end{tabular}

Table III. Association between demographic characteristics and depression among gastroenterologists

\begin{tabular}{|c|c|c|c|c|c|}
\hline Participant characteristics & Number & Normal & Borderline depression & Overt depression & $P$-value \\
\hline Gastroenterologist & 63 & $50(79.4 \%)$ & $11(17.5 \%)$ & $2(3.2 \%)$ & \\
\hline \multicolumn{6}{|l|}{ Age [years]: } \\
\hline$\leq 40$ & 6 & $4(66.66 \%)$ & $1(16.66 \%)$ & $1(16.66 \%)$ & \\
\hline $41-50$ & 29 & $22(75.86 \%)$ & $6(20.69 \%)$ & $1(3.44 \%)$ & 0.289 \\
\hline$>50$ & 28 & $24(85.71 \%)$ & $4(14.28 \%)$ & 0 & \\
\hline \multicolumn{6}{|l|}{ Employment: } \\
\hline Government & 51 & $41(80.39 \%)$ & $8(15.68 \%)$ & $2(3.92 \%)$ & \\
\hline Private & 10 & $7(70)$ & $3(30 \%)$ & 0 & 0.729 \\
\hline Retired & 2 & $2(100.00 \%)$ & 0 & 0 & \\
\hline \multicolumn{6}{|l|}{ Service length [years]: } \\
\hline$\leq 10$ & 6 & $5(83.33 \%)$ & 0 & $1(16.66 \%)$ & \\
\hline $11-15$ & 11 & $7(63.63 \%)$ & $3(27.27 \%)$ & 1 (9.09\%) & 0.095 \\
\hline $16-20$ & 19 & $17(89.47 \%)$ & $2(10.52 \%)$ & 0 & \\
\hline$>20$ & 27 & $21(77.78 \%)$ & $6(22.22 \%)$ & 0 & \\
\hline \multicolumn{6}{|c|}{ Length of practice in gastroenterology [years]: } \\
\hline$\leq 5$ & 8 & $4(50.00 \%)$ & $3(37.50 \%)$ & $1(12.50 \%)$ & \\
\hline $6-10$ & 14 & $11(78.57 \%)$ & $2(14.28 \%)$ & $1(7.14 \%)$ & 0.251 \\
\hline $11-20$ & 29 & $24(82.76 \%)$ & $5(17.24 \%)$ & 0 & \\
\hline$>20$ & 12 & $11(91.66 \%)$ & $1(8.33 \%)$ & 0 & \\
\hline
\end{tabular}


lence of anxiety was higher among gastroenterologists in government service - 14 (27.45\%), and it was lowest among those with service length more than 20 years - 3 (11.11\%), but the difference was not significant. Depression was also more common among gastroenterologists of the 41-50-years age group - 7 (24.13\%), doing government service - 10 (19.60\%), with service length $\leq 15$ years -5 (29.41\%), and working as specialist less than or equal to 10 years $-7(31.82 \%)$, but the difference was not significant.

\section{Discussion}

In this study, the response rate was about 38\%, which was higher than the report from India [10] but lower than the report from Pakistan [11]. This lower response rate may be due to their excess workload, lack of personal time for relaxation, and their unwillingness to be screened and stigmatized. About onefourth of gastroenterologists had symptom scores consistent with some sorts of anxiety (borderline and overt). A similar prevalence of anxiety was seen among graduate and postgraduate doctors in China [7], but our prevalence was much lower than the report from Pakistan [11]. The prevalence of anxiety among postgraduate residents in Bangladesh was also much lower than in the current study. In Bangladesh, the number of gastroenterologists is not adequate for the total population. In addition to medical consultation, they have to perform diagnostic and therapeutic procedures with limited logistics support. This work environment, e.g. excess workload, a high level of responsibility, and a fear of making mistakes, may influence them to have anxiety and stress. Reports from China, Poland, and Turkey also showed a relationship between anxiety and a hostile working environment among physicians [7, 20, 21]. In the current study, the prevalence of anxiety decreased with an increase in age. Also, anxiety was more prevalent among gastroenterologists in government service and those with shorter working experience. In contrast, it was less prevalent among those having a service length of more than 20 years. A report from Saudi Arabia also showed a higher prevalence of anxiety among young physicians [22]. One American report showed that junior gastroenterologists, mostly related to endoscopy practice, had more stress and anxiety than seniors [23]. Patient satisfaction, expectation from controlling authority, acquisition of newer techniques, workload, and uncertainty regarding career build-up produce stress and anxiety among young gastroenterologists. Occupational stress is a recognized cause of anxiety [24]. It is usual that after 20 years of service, physicians are already established and usually do not have to think of career build-up. Another factor responsible for lower baseline stress among older physicians is the individual adaptations to the stressful workplace, which they learn during their years of training and practice. In contrast, reports from Malaysia and Pakistan showed that the prevalence of anxiety does not differ with service length $[7,11]$.

In this study, about one-fifth of gastroenterologists had some sort of depression (borderline and overt), which was lower than some reports in which surveys were done among postgraduate residents, general physicians, and a group of graduate and postgraduate doctors $[6,7,11]$. It was higher than one report from Bangladesh [12] and higher than previous reports from the USA, Canada, Britain, Norway, Japan, and Benin, where the prevalence of depression among physicians ranged from $8.8 \%$ to $15.5 \%$ [25-30]. The small sample size, single specialty of physicians, and the difference in mental state assessment instrument may cause this difference. In our series, depression was more prevalent among the younger group of gastroenterologists. An increased prevalence of mental disorders, including depression, was also seen among young doctors and medical students in Australia [31]. Conversely, age was not found to influence causation of depression among Malaysian emergency medical doctors and general practitioners in the UK $[8,30]$. High workload, less professional experience, inadequate professional training, and uncertainty of future career building might influence their mental health. In the current study, depression was more prevalent among gastroenterologists working in government service. Also, a small number of gastroenterologists in our series were in private service, which may be an issue. Reports from China, Poland, and Turkey showed that a hostile working environment increases the chance of depression among doctors [7, 19, 20]. Gastroenterologists with service length $\leq 15$ years suffered more from depression, consistent with a report from Pakistan [11]. The doctor-patient relation in Bangladesh is not good. The dissatisfaction of patients and authority also play a role in the disturbed mental health of physicians. This is consistent with the American report [23].

The current study had some limitations: (1) the sample size was relatively small; (2) information on working hours per week, job satisfaction, violence at the workplace, family life, income, hobbies, time for relaxation and recreation, etc. were not included; and (3) there was no control group.

\section{Conclusions}

Anxiety and depression among gastroenterologists are more prevalent than in the general population. Gas- 
troenterologists in younger age groups, working in the government sector, and with less experience working as specialists are more vulnerable. Disturbed mental health negatively affects health care delivery. Further studies should be done to determine the risk factors behind anxiety and depression among gastroenterologists so that adequate measures can be taken.

\section{Acknowledgments}

The authors would like to thank the gastroenterologists of Bangladesh for their contribution and participation in this study.

\section{Conflict of interest}

The authors declare no conflict of interest.

\section{References}

1. Lepine JP, Briley M. The increasing burden of depression . Neuropsychiatr Dis Treat 2015; 7 (Suppl): 3-7.

2. Geneva: World Health Organization. Depression and Other Common Mental Health Disorders: Global Health Estimates. https://apps.who.int/iris/bitstream/handle/ 10665/254610/WHO-MSD-MER-2017.2-eng.pdf; 2017 [Accessed 7 Jan. 2020].

3. National Institute of Mental Health, Dhaka. National Mental Health Survey of Bungladesh,2018-19 Provisional Fact Sheet, https://www.who.int/docs/default-source/searo/bangladesh/ pdf-reports/cat-2/nimh-fact-sheet-5-11-19.pdf;2019 [accessed 12 January 2020].

4. Gerada C. Doctors, suicide and mental illness. BJPsych Bull 2018; 42: 165-8.

5. Bailey E, Robinson J, McGorry P. Depression and suicide among medical practitioners in Australia. Intern Med J 2018; 48: 254-8.

6. Mata DA, Ramos MA, Bansal N, et al. Prevalence of depression and depressive symptoms among resident physicians: a systematic review and meta-analysis. JAMA 2015; 314: 2373-83.

7. Gong Y, Han T, Chen W, et al. Prevalence of anxiety and depressive symptoms and related risk factors among physicians in China: a cross-sectional study. PLoS One 2014; 9: e103242.

8. Yahaya SN, Wahab SFA, Yusoff MSB, et al. Prevalence and associated factors of stress, anxiety and depression among emergency medical officers in Malaysian hospitals. World J Emerg Med 2018; 9: 178-86.

9. Dave S, Parikh M, Vankar G, Valipay SK. Depression, anxiety, and stress among resident doctors of a teaching hospital. Indian J Soc Psychiatry 2018; 34: 163-71.

10. Grover S, Sahoo S, Bhalla A, Avasthi A. Psychological problems and burnout among medical professionals of a tertiary care hospital of North India: a cross-sectional study. Indian J Psychiatry 2018; 60: 175-88.

11. Atif K, Khan HU, Ullah MZ, et al. Prevalence of anxiety and depression among doctors; the unscreened and undiagnosed clientele in Lahore, Pakistan. Pak J Med Sci 2016; 32: 294-8.

12. Sadiq MS, Morshed NM, Rahman W, et al. Depression, anxiety, stress among postgraduate medical residents: a cross sectional observation in Bangladesh. Iran J Psychiatry 2019; 14: 192-7.

13. Tareq SR, Likhon RA, Rahman SN, et al. Depression among medical students of Bangladesh. Mymensingh Med J 2020; 29: 16-20.

14. Pal K. Relationship between anxiety and work stress among senior and junior doctors. 2019, DOI: 10.13140/RG.2.2. 26570.93121

15. Ruitenburg MM, Frings-Dresen MH, Sluiter JK. The prevalence of common mental disorders among hospital physicians and their association with self-reported work ability: a cross-sectional study. BMC Health Serv Res 2012; 12: 292-8.

16. Fahrenkopf AM, Sectish TC, Barger LK, et al. Rates of medication errors among depressed and burnt out residents: prospective cohort study. BMJ 2008; 336: 488-91.

17. Pereira-Lima K, Mata DA, Loureiro SR, et al. Association between physician depressive symptoms and medical errors: a systematic review and meta-analysis. JAMA Netw Open 2019; 2: e1916097.

18. Koutsimani P, Montgomery A, Georganta K. The relationship between burnout, depression, and anxiety: a systematic review and meta-analysis. Front Psychol 2019; 10: 284.

19. Zigmond AS, Snaith RP. The hospital anxiety and depression scale. Acta Psychiatrica Scandinavica 1983; 67: 361-70.

20. Merecz D, Drabek M, Mościcka A. Aggression at the workplace: psychological consequences of abusive encounter with coworkers and clients. Int J Occup Med Environ Health 2009; 22: 243-60.

21. Aytaç S, Dursun $S$. The effect on employees of violence climate in the workplace. Work 2012; 41 Suppl 1: 3026-31.

22. Alzahrani A, Alghamdi EA, Alyamani MN, et al. Generalized anxiety disorder among physicians in Jeddah, Saudi Arabia: prevalence and determinants. Int J Med Res Prof 2016; 2: 140-6.

23. Keswani RN, Taft TH, Coté GA, Keefer L. Increased levels of stress and burnout are related to decreased physician experience and to interventional gastroenterology career choice: findings from a US survey of endoscopists. Am J Gastroenterol 2011; 106: 1734-40.

24. Sun W, Fu JL, Chang Y, Wang L. Epidemiological study on risk factors for anxiety disorder among Chinese doctors. J Occup Health 2012; 54: 1-8.

25. Lloyd S, Streiner D, Shannon S. Burnout, depression, life and job satisfaction among Canadian emergency physicians. J Emergency Med 1994; 12: 559-65.

26. Ofili AN, Asuzu MC, Isah EC, Ogbeide O. Job satisfaction and psychological health of doctors at the University of Benin Teaching Hospital. Occup Med 2004; 54: 400-3.

27. Schwenk TL, Gorenflo DW, Leja LM. A survey on the impact of being depressed on the professional status and mental health care of physicians. J Clin Psychiatry 2008; 69: 617-20.

28. Vaglum P, Falkum E. Self-criticism, dependency and depressive symptoms in a nationwide sample of Norwegian physicians. J Affect Disord 1999; 52: 153-9.

29. Wada K, Yoshikawa T, Goto T, et al. Association of depression and suicidal ideation with unreasonable patient demands and complaints among Japanese physicians: a national cross-sectional survey. Int J Behav Med 2011; 18: 384-90. 
30. Chambers R, Campbell I. Anxiety and depression in general practitioners: associations with type of practice, fund holding, gender and other personal characteristics. Family Practice 1996; 13: 170-3.

31. Wu F, Ireland M, Hafekost K, Lawrence D. National mental health survey of doctors and medical students, Australia, Beyond Blue 2013; 156.

Received: 11.02.2021

Accepted: 14.03.2021 